\title{
TECHNIQUES OF ARCHITECTURAL-PLANNING ACCENTATION OF TOURIST ATTRACTIONS - SIGNIFICANT MONUMENTS OF ARCHITECTURE AND RENOVATION OF THEIR TERRITORIES IN RURAL COMMUNITIES
}

\author{
(C) Chyzhevska L., 2020
}

The article discusses various options for the solution and arrangement of the tourist and recreational nature of rural areas and settlements. The application of the principle of the scenario plan to the organization and improvement of planning and visual ties between individual elements of the space of the territory of the community, rural settlements, and their separate parts is processed.

The author relies on research and generalizations during field surveys or the implementation of design work using software and hardware based on GIS technologies, contributed to the formulation of the method of implementing a scenario approach to laying or appropriate design of tourist routes, routes of perception of attractive objects (first of all, architectural ) and surrounding landscapes. To fully reveal the role of these leading landmarks, methods of renovating their territories and the environment are proposed.

Key words: tourist and recreational space, scenario plan, route of visual perception, attractive object, territory renovation.

\section{Problem statement}

Realization of the tourist and recreational potential available in the united territorial communities is closely connected with opening and use of various attractions to which first of all belong: 1) monuments of national architecture; 2) open-air museums and ethnographic complexes; 3) castle complexes; 4) noble estates; 5) palace and park ensembles; 6) historical, cultural and spiritual centers. This should be achieved primarily through urban planning through the development and provision in the documentation for spatial planning of activities aimed at receiving vacationers and tourists.

\section{Purpose of the article}

Effective use of the existing historical and cultural potential in the interests of territorial communities, which constitute the architectural monuments, involves the development and implementation of architectural and planning techniques for the visual perception of such objects and their inclusion in the full tourist and recreational activities.

Development and development of methods of spatial and architectural-planning organization of the recreational environment of rural areas and settlements is based on research and analysis of research and design practices, which determine to do so consistently in terms of relevant 
administrative-territorial or functional-organizational entities: community, settlement the territory of a separate recreational element: a resort-sanitary or tourist-recreational institution, an array of cottage recreational buildings, a separate farm or peasant farm, a separate farmstead or a planned combined group of such estates.

\section{Basic material}

Territorial tourist - recreational space of the community is determined by studying and working on the main structural elements, including: the territory of attractive objects and identified components of the landscape as a recreational and tourist direction and those classified as a cultural landscape. Planning and visual connections are established between these elements in order to form expressive perspective species, as well as the fullest disclosure of natural advantages and features of the surrounding landscape, and ultimately - the formation of an image that is the sum of visual perceptions of a particular area or settlement.

The role of a kind of introduction of travelers into the recreational space of the united territorial community can be played by elements of arrangement of tourist - recreational character of separate landscape components or recreation areas located near transit roads. In practice, there are often cases when recreation areas with information stands are arranged above the roads, inviting to use the recreational and tourist attractions of the territory of this community. This technique allows you to create an attractive image of the united territorial community and its tourist and recreational potential, as well as to invite guests following the transit. (Examples are similar arranged places: in the village of Tarakaniv, Rivne region, near the Kyiv-Chop highway, and in the village of Pustovoytivka, Sumy region, above the Sumy-Kyiv road, and others).

Carried out with the direct participation of the author project and research and development of spatial planning of rural areas and settlements confirmed the feasibility of developing and applying the principle of the scenario plan to organize and improve planning and visual links between the main elements of community space, rural settlements, their individual structural elements. - recreational direction and attractive objects associated with the development and definition of appropriate architectural and planning compositional techniques. All existing planning connections, which are manifested in the existing or designed road-street or walking network, are considered as routes of perception of the surrounding cultural and natural landscape. The essence of establishing and applying the methods of architectural and planning organization of the space of the community is to ensure the fullest identification and disclosure of aesthetic qualities of built-up and unbuilt-up spaces. This can be most effectively done through the implementation of a special project action, which is based on the principles of the scenario principle for the construction or arrangement of pedestrian, walking trails, repair and improvement of the existing road and street network.

The realization of the script principle consists in the consciously programmed creation in the traveler of the impression of the uniqueness and uniqueness of the area, which should be achieved through the perception of a kind of video series of spectator images revealed from different views. Such viewpoints in the form of platforms, stops or just a kind of view windows are arranged along the entire route of movement of vacationers from the moment of entering the community or settlement to achieve the goal of travel - the location of a key attractive object - an architectural monument. 
The planning of the direction of movement and, accordingly, the route of perception are somewhat limited by the existing road-street network. The analysis of such a route dictated by the existing situation should be carried out from the standpoint of the peculiarities of human perception of the environment.

An analysis of project practice (for example, the work of the Lviv Institute "Mistoproekt": "Development Plan of Kremenets-Pochaiv region", as well as "Analysis of the current state and determination of recreational potential of the tract" Chervonogorod "near the village Nyrkiv Zalishchyk district Ternopil region) shows that in order to enhance the effect of the perception of travel should be planned other than existing streets and roads, directions, especially for hiking. This is how the route from the outskirts of the village of Nyrkiv to the outskirts of the village of Nagoryany was designed. Along the route of travel and, accordingly, visual perception, it is possible to see the general view of the tract "Chervonogorod" with the surrounding hilly landscape, some panoramic views of architectural monuments against the background of the natural environment, views of architectural monuments or their ruins in the natural environment. making historical monuments, physically visit two waterfalls on the river Dzhuryn. (Fig. 1).

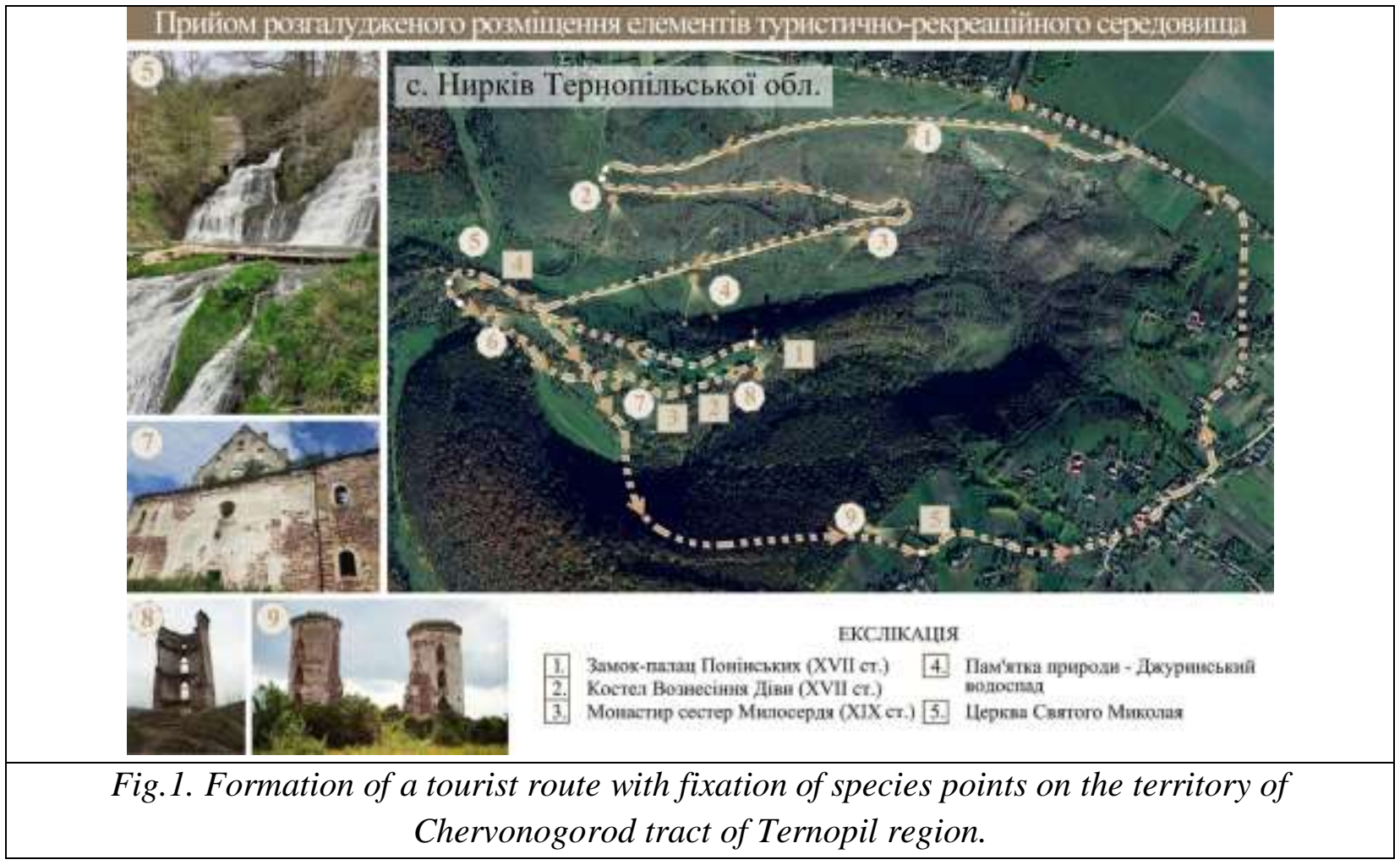

Of major importance is the decoration of the main transport artery - the road that leads through the community to the most attractive object or objects. The beginning of such planning connection of the territory of an attractive object with the environment should be accentuated and landscaped by architectural and planning means: it should carry the corresponding information and image load. The routes of perception of expressive landscape species with or without attractive objects should be planned and cleared along the route.

In this regard, in order to enhance the positive effect of the perception of the route should be guided by approaches that meet the principle of "centrifugal", which was formulated by the authors of the book "Architectural expressiveness of the village center." The essence of the principle is to strengthen the architectural planning and compositional means of the feeling of approaching the climax - an attractive object, as a whole trip. Only in terms of the content of the book it referred 
to the public center of the village or the House of Culture with the area in front of it (Gudchenko, Tkachikov and Khokhol, 1980).

Using the experience of architectural and urban science from the standpoint of visual perception of landscape spaces and architectural objects, the following approaches to the arrangement of visual axes are developed.

ID Rodichkin recommends for the roads-tracks of perception, leading to places of recreation and recreation, to use the following techniques of landscaping, which have a park character: to form the surrounding landscape, using contrasting in shape and color design elements, adhering to the smooth perception of the audience and take into account, that the main components of the roadside landscape are areas with a clear plastic relief and large arrays of greenery (Rodichkin, I. D., 1977).

The design of walking trails should take into account the need to subordinate the applied techniques of park design to the perception of the surrounding landscape, taking into account the rhythm of movement of potential vacationers during walks. That is why in the landscape plan of the territory of OTG should be planned after 1.5-3.0 km of species sites for the perception of the next components of the landscape (according to the classification, as suggested by V. Stauskas (1977).

Tourist road and walking routes in the plains should be as close as possible to the landscape components (reservoirs and forests), and in terms of more pronounced terrain - to pass on elevated levels or on the edges of thalwegs and in places of turns of folds or curves of rivers, and finding monuments of architecture, archeology and history (Verkalets, 2014). One-, two-, and three-day routes are laid along the linear components of the landscape, between reservoirs and monuments and have a rhythm of stops in accordance with the way of overcoming the route (bus, car, bicycle, boat, rubber transport, pedestrian); the key points of the routes are the places where tourists spend the night.

Urban science has identified the main provisions related to human perception of architectural objects, taking into account the distance to them (Ikonnikov, 1972). In particular, in the work of EL Belyaeva "Architectural and spatial environment of the city as an object of visual perception" (Belyaeva, 1977) specified and formalized approaches to problems of perception, linking such geometric parameters as: distance to the object of perception, the height of the spectator barrier and vertical angle of view.

The author's research and generalizations during field surveys or project work carried out using a graphoanalytical method using software and hardware based on GIS technologies, allowed to formulate the following method of implementing a scenario approach to the development of design or appropriate design of tourist routes-routes of perception architectural objects and surrounding landscapes.

The distance that the traveling spectator has to cover to the goal of his trip - an attractive object, is proposed to be divided into six segments. The first is a part of the route, which is from $1500 \mathrm{~m}$ to $500 \mathrm{~m}$ with a viewing angle of 20 or less. At this distance, in general, the average height of the architectural object $(10-15 \mathrm{~m})$ is perceived only as an element of the overall landscape panorama. High-rise vertical accents of historical buildings are more clearly visible: bell towers of temples and monasteries or high defensive towers. In fact, this is only the first visual contact that captures the purpose of the trip.

The second segment is a part of the route at a distance of 500 to $300 \mathrm{~m}$ with a viewing angle in the range from 20 to 30: the silhouette and panorama are specified, the connection of architecture with the natural environment is viewed. 
The third segment is the distance from $300 \mathrm{~m}$ to $180 \mathrm{~m}$ (angle of view from 30 to 50). From this distance the silhouettes of buildings are clearly perceived, the contours of individual buildings or their parts are viewed. High vertical elements are perceived as landmarks in space that clearly indicate the location of an attractive object.

The fourth segment is the distance from $180 \mathrm{~m}$ to $120 \mathrm{~m}$ (angle of view from 50 to 80 ). The silhouette of buildings is filled with the content of perception: the ratios and proportions of their parts are viewed.

The fifth segment is the distance from $120 \mathrm{~m}$ to $70 \mathrm{~m}$ (angle of view from 80 to 140). Large plastic facades become objective, it is possible to form an idea of the image of a single object of architecture or the whole architectural ensemble.

The sixth segment is the distance that is close to the object (from $70 \mathrm{~m}$ to $30 \mathrm{~m}$ ) equal to or less than the height of the architectural object (angle of view from 140 to 280 and more). The details are considered, the impression of individual architectural and artistic elements and samples of monumental and decorative arts is formed, the state of preservation of the monument is assessed the purpose of the trip is achieved.

Understanding these features becomes crucial for the process of establishing places of fixation or monuments of viewpoints along the route of travel to an attractive object. As practice shows, the first two sectors of the route are considered during the development of tourist routes in the framework of project work on spatial planning of the territories of the united territorial communities, the next two (third and fourth) - during the development of master plans and the last two - during the development of detailed plans of territories of the central parts of settlements or territories of sights of architecture. The essence of the proposed method of implementing the scenario approach is to determine at least one viewpoint or viewport in each of the selected sectors of the route-route of perception of recreational spaces with attractive objects.

The plan of the route from the standpoint of creating a programmed change of video, alternating general perspectives with plot perspectives, in which the tourist attraction is viewed, and then - perceived in fragments, in detail, should be created on the same principle in individual settlements. It is in the territories of settlements to the greatest extent the principle of a scenario approach to the formation of a recreational environment will interact with the principle of spatial emphasis on the leading tourist attractions. This is evident when such an attraction is an architectural landmark. The main practical methods in the implementation of this principle are to open the monument for perception from both distant and near species. This is done by clearing unnecessary background greenery or demolishing temporary, often non-capital structures, usually for economic purposes. It should be noted that in the vast majority of cases, the monuments were used to accommodate and equip administrative, educational, military institutions, economic, industrial, warehouse facilities. Because of this, and often for ideological reasons, the monuments were deliberately "humiliated" by architectural and planning methods. For example: in front of the main facade of the Stetsky palace in the village of Velyki Mezhyrychi in Rivne region (monument of the first half of the XIX century) a mass grave was arranged and a number of coniferous trees were planted between them, completely covering the expressive central portico (Fig. 2); the territory of the monument of the beginning of the XYII century of the palace-fortress of the Konetspolskis in the village of Pidhirtsi in the Lviv region is crossed by a village street, separating the church-family tomb from a single ensemble; to the monument of the turn of the XIX - XX centuries of the Church of the Holy Intercession in the village of Parkhomivka in Kyiv region, the production premises of the agricultural enterprise are located almost close; inappropriate extensions were made to one of 
the outbuildings of the Valevsky palace complex in the village of Verkhivnya in the Zhytomyr Region (architectural monuments of the first half of the 19th century), etc.

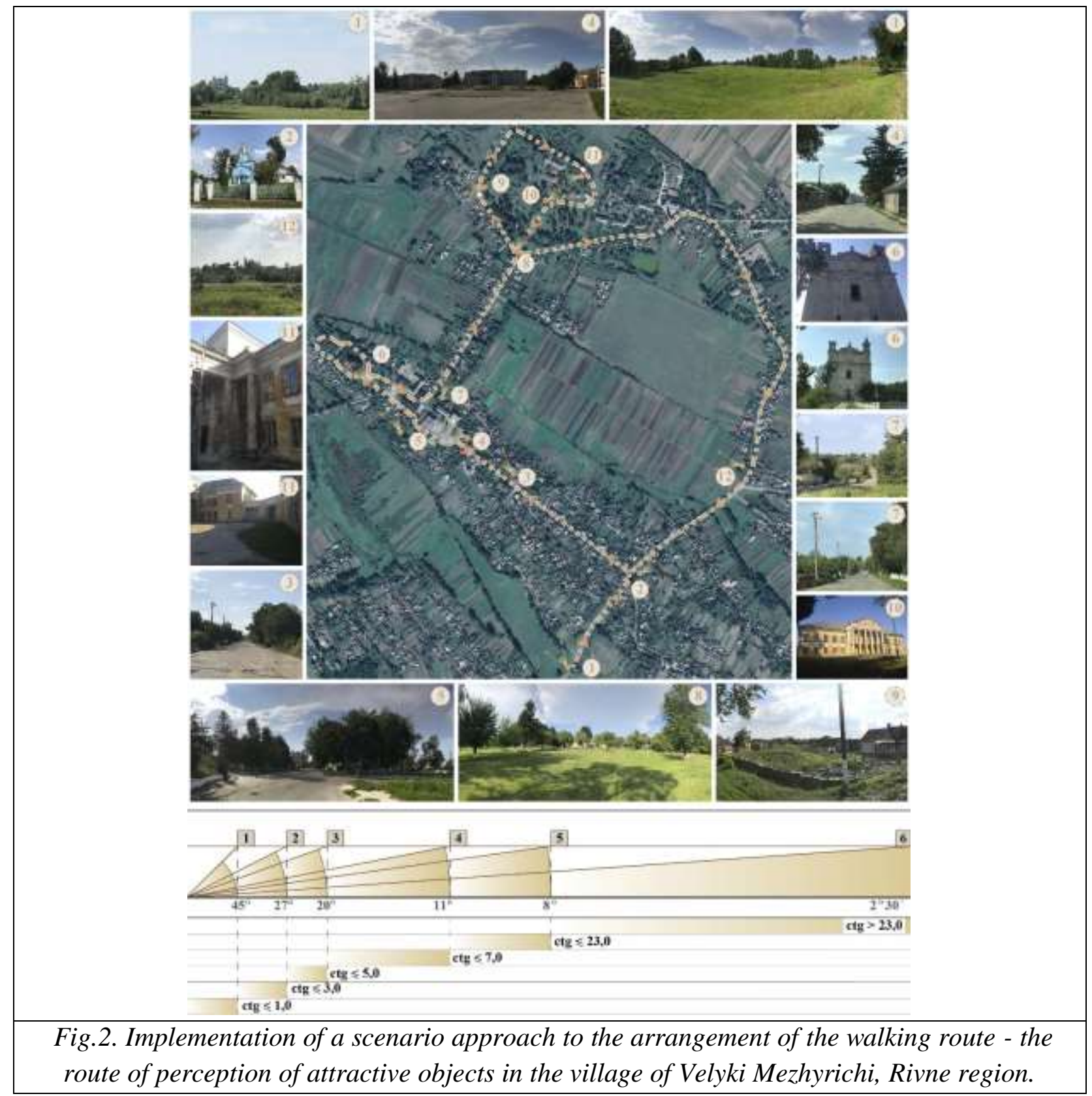

For such and similar objects of architectural heritage in the conditions of rural settlements it is necessary to apply methods of renovation:

a) changes in the road and street network, traffic patterns on the territory of the monument or near it, reproduction of the integrity of the planning structure of the territory of the monument;

b) restoration of the lost and destroyed elements of the historical architectural ensemble of the monument by means of reconstruction and restoration with the use of elements of landscaping and landscaping;

c) clearing of green plantings that cover the facades of buildings or species landscape perspectives from attractive objects;

d) demolition of outbuildings, decor and landscaping elements, not made in the historical style. (Fig. 3). 


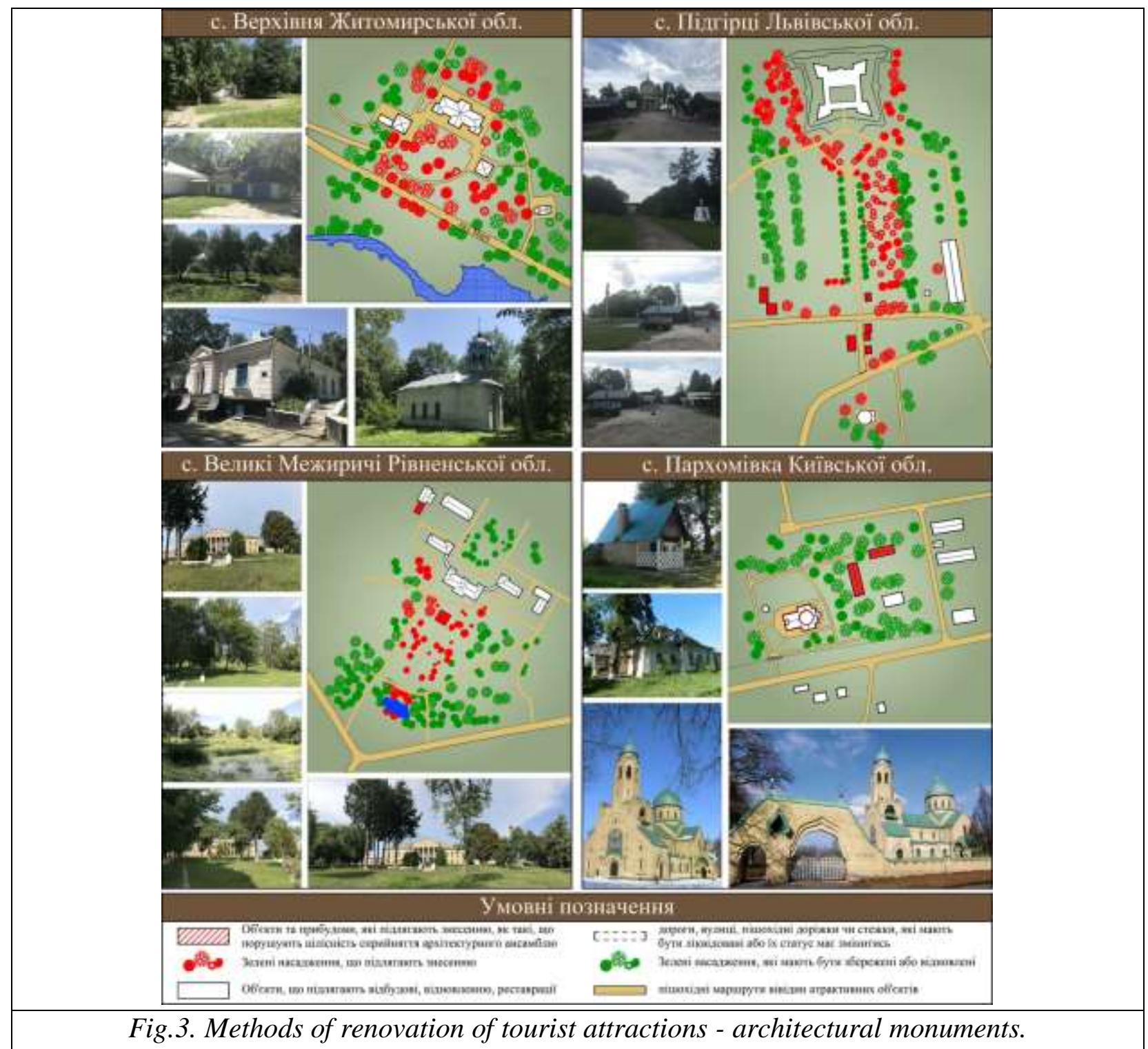

The proposed measures for the renovation of architectural monuments - leading tourist attractions not only contribute to their emphasis in the planning structure of settlements, but also essentially become the first stage of reconstruction of such facilities, which are the key to their full use in modern life of local communities.

\section{Conclusions}

The practical application of the developed techniques should correspond to the levels of tasks and the scale of the topographic and geodetic basis of spatial planning projects. The proposed segments of perception of attractive objects, which correspond to the following types of urban planning documentation: 1st and 2nd segments, taking into account the distance to the monument, can be considered when developing a scheme of spatial planning of the community; The 3rd and 4th segments correspond to the level of solving project tasks during the development of the general plan of the settlement; The 5th and 6th segments directly solve the arrangement of the area of perception of an attractive object, which can be implemented within the framework of the developed detailed plan of the territory of the central part of the settlement or the territories that are a protected area of the monument.

Techniques of renovation of monument sites contribute to the implementation of the techniques of the scenario approach and become the first stage of reconstruction of these objects. 


\section{References}

Belyaeva, E. L., 1977. Architectural and spatial environment of the city as an object of visual perception. Moskva: Stroyizdat.

Gudchenko, Z. S., Tkachikov, I. N. and Khokhol, Yu. F., 1980. Architectural expressiveness of the village center. Kiev: Budivelnik.

Ikonnikov, A. V., 1972. City architecture. Aesthetic problems of composition. Moskva: Stroyizdat, Kuznetsky Most.

Rodichkin, I. D., 1977. Man, environment, rest. Kiev: Budivelnik.

Stauskas, V. P., 1977. Town-planning organization of districts and recreation centers. Leningrad: Stroyizdat.

Verkalets, I. M., 2014. Architectural and planning organization of recreational landscapes using methods for assessing their aesthetic properties (on the example of Ivano-Frankivsk region): author's ref. dis. PhD. Poltava: PNTU. 